\title{
TO ASSESS THE BALANCE CONTROL OF ELDERLY WITH SYMPTOMATIC KNEE OSTEOARTHRITIS IN A SELECTED COMMUNITY AT KANYAKUMARI DISTRICT
}

Mrs. Janet. J* | Dr. J. Jasmine **

* Professor, Saraswathy College of Nursing, Kerala, India.

** Professor, Theresa Post Graduate \& Research Institute of Health Sciences, Puducherry, India. DOI: http://doi.org/10.47211/idcij.2020.v07i03.016

\section{ABSTRACT}

Received $10^{\text {th }}$ June 2020, Accepted $25^{\text {th }}$ June 2020, Available online $10^{\text {th }}$ July 2020.

Osteoarthritis (OA) is one of the most prevalent musculoskeletal impairments worldwide, affecting $30-40 \%$ of the population by the age of 65 years. It is a major cause of impairments and disability among the elderly and poses a significant economic burden on the community. Individuals with knee OA suffer progressive loss of function displaying increasing dependency in walking, stair climbing and other lower extremity task. The problem under the study was to assess the balance control of elderly with symptomatic knee osteoarthritis from selected community area at Kanyakumari district. The objectives of the study were to assess the balance control of elderly with symptomatic knee osteoarthritis, and to find out the association of balance control and selected demographic variables. The descriptive research design was adopted for this study. The population selected for the study comprised of elderly with symptomatic knee osteoarthritis from selected community area at Kanyakumari district. 60 elderly were selected by non-probability purposive sampling technique. The Berg Balance Scale was used to assess the balance control. Frequency, percentage, chi square test was used to analyse the study. The result of the study revealed that 59 (98.33\%) of the elderly suffered with moderate level of balance control. The findings revealed that statistically significant association was found between age and history of doing exercise and balance control of the elderly at $p=0.05$. No association was found between functional ability and other demographic variables.

Key words: Osteoarthritis (OA), musculoskeletal impairments, Kanya kumari.

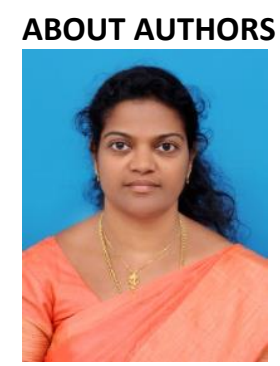

Author Janet J. is Professor at Saraswathy College of Nursing, Kerala. She has presented papers at various seminars and conferences.

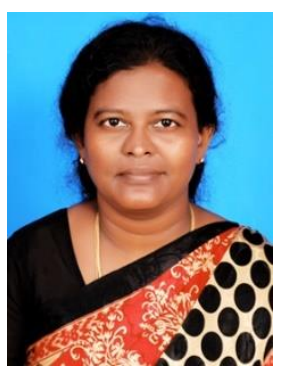

Author Dr. J Jasmine is working as Professor, Theresa Post Graduate \& Research Institute of Health Sciences; Puducherry, India. She is a Research Guide for PG Students and Ph.D. Scholars. She has presented more than 30 papers in various National and International conferences. 


\section{INTRODUCTION}

Osteoarthritis (OA) is a major cause of disability among elderly worldwide. According to WHO worldwide $9.6 \%$ of men and $18.0 \%$ of women aged over 60 years has symptomatic OA. The prevalence of symptomatic knee OA is estimated as $12 \%$ of the US adults older than 65 years of age. The prevalence of OA in India is $22 \%-39 \%$. It is reported more among women than men (Arthritis Foundation of India). Among adults 60 years of age or older the prevalence of symptomatic knee OA is approximately $10 \%$ in men and $13 \%$ in women. The number of people affected with symptomatic $O A$ is likely to increase due to the aging of the population and the obesity epidemic.

Balance is a complex function that requires the integration of sensory information of the position of the body and the ability to make proper motor responses to body movement ${ }^{3}$. Balance is essential for maintaining postural stability while performing daily activities ${ }^{4}$, and loss of balance is a common cause of falls in older people. Balance function is the ability to maintain the center of mass at the base of support. It is the interaction among sensory inputs from proprioception, visual and vestibular systems, motor systems (such as muscle strength and muscle activity), and cognitive components (Kim et al., 2011; Sturnieks et al., 2008). Balancing prevents falls and is required for many functional activities (Sibley et al., 2013). Reduced balance function is associated with an increased risk of falling, which is one of the leading causes of hospital admissions of elderly people, and could lead to other consequences such as fracture, joint dislocation, soft-tissue injury, loss of independence, and mortality (Pandya et al., 2007).

Patients with knee OA typically have impairment of proprioception within the joint or weakness in the quadriceps muscles as compared with those without knee OA. These impairments associated with the disease may explain the poorer balances within these patients. More than $50 \%$ of all OA patients and $64 \%$ of female OA patients report falling within one year ${ }^{5},{ }^{7}-9$. Approximately $60 \%$ to $80 \%$ of patients with knee OA report joint instability. Poor balance control, especially during standing or movement, is one risk factor for falls that could be addressed in the knee OA population. Better standing balance has been associated with increased quadriceps muscle strength, more advanced radiographic disease severity, less varus alignment, less pain, and better proprioception (Hunt et al., 2010). Impaired balance control has been suggested to be one of the most important risk factors of falls in arthritis patients. Reduced proprioceptive acuity of the involved joints and increased postural sway in standing have been identified in patients with lower limb OA.(Williams et al.,) The purpose of this study is to evaluate the balance control of elderly with symptomatic knee osteoarthritis. Studying balance control is required to support patient independence and it has rising as key to evaluate the health status of the elderly.

\section{PROBLEM STATEMENT}

A descriptive study to assess the balance control of elderly with symptomatic knee osteoarthritis in a selected community area at Kanyakumari District.

\section{OBJECTIVES}

- To assess the balance control of elderly with symptomatic knee osteoarthritis.

- To find out the association of balance control of elderly with symptomatic Knee Osteoarthritis and selected demographic variable

\section{MATERIALS AND METHOD}

Research approach: The quantitative research approach

Research design: Descriptive research design was adopted for this study

Setting of the study: Study was conducted in selected community area

Population: elderly who were living in selected community area with symptomatic Knee Osteoarthritis

Sample size: Total sample size for this study was 60 elderly with symptomatic knee OA.

Sampling technique: Subjects of the sample will be selected by non-probability purposive sampling technique

\section{CRITERIA FOR SAMPLE SELECTION}

Inclusion criteria:

Elderly with symptomatic OA

- Age above 60 years.

- Knee pain in unilateral or bilateral

- Willing to participate in the study

- Available during data collection period

Exclusion criteria

- Unresolved neurological disorder

- History of major knee trauma

- underwent hip or knee replacement 


\section{ARTICLES}

\section{DEVELOPMENT OF TOOL}

Section A includes demographic data of the geriatrics such as age, gender, education, occupation, religion and marital status.

Section B includes clinical data such as BMI, duration of knee pain, which knee is affected, and history of doing exercise.

\section{DEVELOPMENT OF TOOL}

Section A includes demographic data of the geriatrics such as age, gender, education, occupation, religion and marital status.

Section B includes clinical data such as BMI, duration of knee pain, which knee is affected, and history of doing exercise.

Section C consisted of Berg Balance Scale (BBS) to assess the balance control of elderly. Balancing ability is currently evaluated in the clinic using composite measures such as the Berg Balance Scale. The berg balance scale consists of 14 items which includes static tasks such as sitting, standing, and movement such as turning and bending. Tasks were scored on a scale of zero (unable to perform or need assistance) to 4 (able to perform independently). Lower scores were given if participants were unable to meet time or distance requirement. Completion of the BBS required two chairs, a ruler, a step or low stool and stop watch. The BBS addressed basic balancing ability in multiple tasks. A high score indicates higher levels of balance control while the low score shows lower levels of balance control.

Total score was interpreted as follows.

$0-20$ - High fall risk

21-40 - Medium fall risk

41-56 - Low fall risk

ANALYSIS:

Table 1

Frequency and percentage distribution of the sample with demographic characteristics

\begin{tabular}{|l|l|l|}
\hline Demographic Variables & No. & $\%$ \\
\hline Age & & \\
\hline $66-65$ years & 9 & 15.0 \\
\hline $66-70$ years & 14 & 23.3 \\
\hline $71-75$ years & 31 & 51.7 \\
\hline $76-80$ years & 6 & 10.0 \\
\hline Gender & & \\
\hline Male & 20 & 33.3 \\
\hline Female & 40 & 66.7 \\
\hline Education & & \\
\hline Illiterate & 12 & 20.0 \\
\hline Primary school & 48 & 80.0 \\
\hline Higher secondary & - & - \\
\hline Graduate & - & - \\
\hline Previous occupation & & \\
\hline Sedentary workers & 7 & 11.7 \\
\hline Moderately sedentary & 24 & 40.0 \\
\hline Heavy workers & 29 & 48.3 \\
\hline Religion & & \\
\hline Christian & 25 & 41.7 \\
\hline Hindu & 35 & 58.3 \\
\hline Muslim & - & - \\
\hline Others & - & - \\
\hline & & \\
\hline
\end{tabular}




\section{ARTICLES}

Table no 2

Frequency and percentage of sample with clinical data Demographic Variables

BMI

Underweight $(<18.5)$

Normal (18.5-24.9)

Overweight $(25-29.9)$

Obese(30 - 39.9)

Duration of knee pain

Less than 3 years

$3-6$ years

$7-10$ years

More than 10 years

Which knee is affected

One knee

Both knees

Are you under any medication for knee pain

Yes

No

Are you following any exercise

Yes

No

If yes,

Walking

Cycling

Jogging

Others

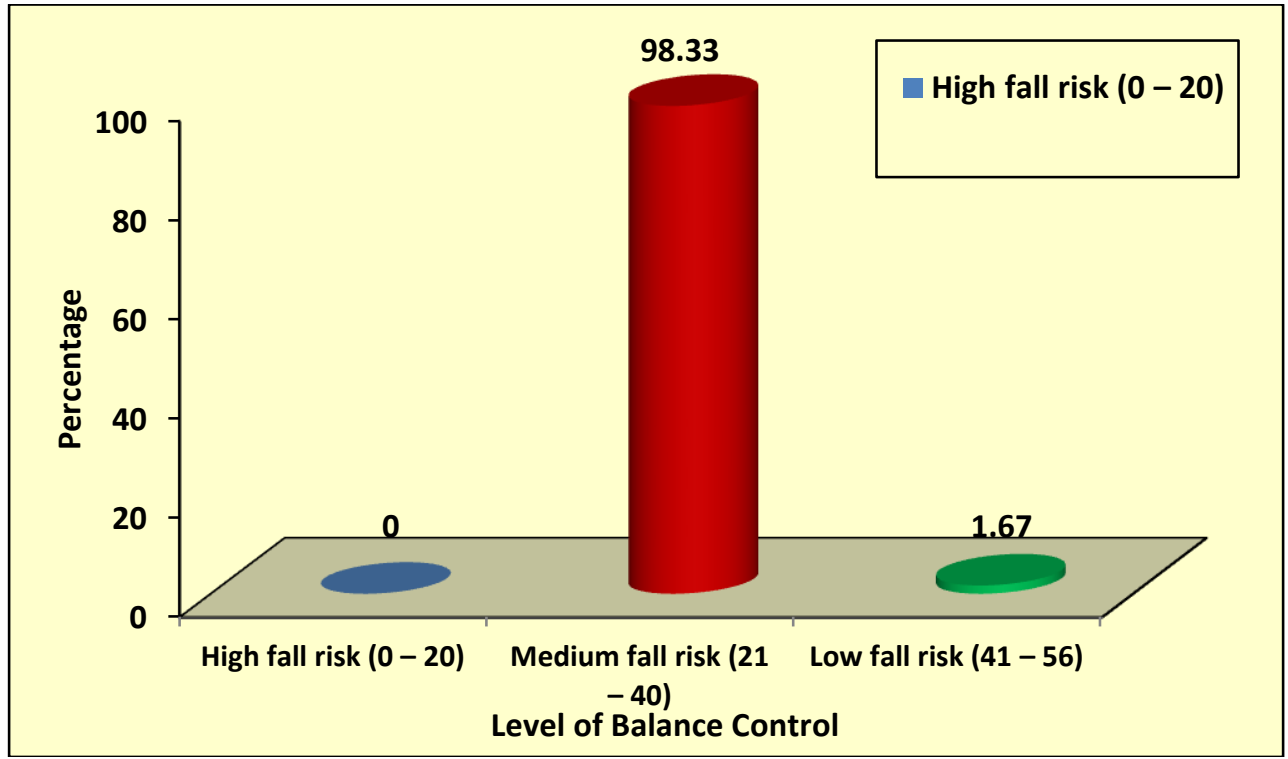

Figure 1 Balance control of samples in percentage 


\section{ARTICLES}

Table no 3: Assessment of balance control among elderly with symptomatic knee osteoarthritis.

$N=60$

\begin{tabular}{|l|l|}
\hline Balance Control & Score \\
\hline Minimum Score & 26.0 \\
\hline Maximum Score & 41.0 \\
\hline Mean & 33.45 \\
\hline Standard Deviation (S.D) & 3.49 \\
\hline
\end{tabular}

Table 4: Association of level of balance control of elderly with symptomatic knee osteoarthritis with their selected demographic variables.

$\mathbf{N}=60$

\begin{tabular}{|c|c|c|c|c|c|c|c|}
\hline \multirow[t]{2}{*}{ Demographic Variables } & \multicolumn{2}{|c|}{ High fall risk } & \multicolumn{2}{|c|}{$\begin{array}{c}\text { Medium fall } \\
\text { risk }\end{array}$} & \multicolumn{2}{|c|}{ Low fall risk } & \multirow{2}{*}{$\begin{array}{l}\text { Chi-Square } \\
\text { Value }\end{array}$} \\
\hline & No. & $\%$ & No. & $\%$ & No. & $\%$ & \\
\hline \multicolumn{7}{|l|}{ Age } & \multirow{5}{*}{$\begin{array}{l}\chi^{2}=9.153 \\
\text { d.f }=3 \\
p=0.027 \\
S^{*}\end{array}$} \\
\hline $66-65$ years & - & - & 9 & 15.0 & 0 & 0 & \\
\hline $66-70$ years & - & - & 14 & 23.3 & 0 & 0 & \\
\hline $71-75$ years & - & - & 31 & 51.7 & 0 & 0 & \\
\hline $76-80$ years & - & - & 5 & 8.3 & 1 & 1.7 & \\
\hline \multicolumn{7}{|l|}{ Gender } & \multirow{3}{*}{$\begin{array}{l}\chi^{2}=2.034 \\
\text { d.f }=1 \\
p=0.154 \\
\text { N.S }\end{array}$} \\
\hline Male & - & - & 19 & 31.7 & 1 & 1.7 & \\
\hline Female & - & - & 40 & 66.7 & 0 & 0 & \\
\hline \multicolumn{7}{|l|}{ Education } & \multirow{5}{*}{$\begin{array}{l}\chi^{2}=0.254 \\
\text { d.f }=1 \\
p=0.614 \\
\text { N.S }\end{array}$} \\
\hline Illiterate & - & - & 12 & 20.0 & 0 & 0 & \\
\hline Primary school & - & - & 47 & 78.3 & 1 & 1.7 & \\
\hline Higher secondary & - & - & - & - & - & - & \\
\hline Graduate & - & - & - & - & - & - & \\
\hline \multicolumn{7}{|l|}{ Previous occupation } & \multirow{4}{*}{$\begin{array}{l}\chi^{2}=1.087 \\
\text { d.f }=2 \\
p=0.581 \\
\text { N.S }\end{array}$} \\
\hline Sedentary workers & - & - & 7 & 11.7 & 0 & 0 & \\
\hline Moderately sedentary & - & - & 24 & 40.0 & 0 & 0 & \\
\hline Heavy workers & - & - & 28 & 46.7 & 1 & 1.7 & \\
\hline \multicolumn{7}{|l|}{ Religion } & \multirow{5}{*}{$\begin{array}{l}\chi^{2}=1.424 \\
\text { d.f }=1 \\
p=0.233 \\
\text { N.S }\end{array}$} \\
\hline Christian & - & - & 24 & 40.0 & 1 & 1.7 & \\
\hline Hindu & - & - & 35 & 58.3 & 0 & 0 & \\
\hline Muslim & - & - & - & - & - & - & \\
\hline Others & - & - & - & - & - & - & \\
\hline
\end{tabular}


Table 5: Association of level of balance control of elderly with symptomatic knee osteoarthritis with their selected clinical variables.

$\mathbf{N}=60$

\begin{tabular}{|c|c|c|c|c|c|c|c|}
\hline \multirow{2}{*}{ Demographic Variables } & \multicolumn{2}{|c|}{ High fall risk } & \multicolumn{2}{|c|}{ Medium fall risk } & \multicolumn{2}{|c|}{ Low fall risk } & \multirow{2}{*}{$\begin{array}{l}\text { Chi-Square } \\
\text { Value }\end{array}$} \\
\hline & No. & $\%$ & No. & $\%$ & No. & $\%$ & \\
\hline \multicolumn{7}{|l|}{ BMI } & \multirow{5}{*}{$\begin{array}{l}\chi^{2}=0.589 \\
\text { d.f }=1 \\
p=0.443 \\
\text { N.S }\end{array}$} \\
\hline Underweight (<18.5) & - & - & - & - & - & - & \\
\hline Normal (18.5 - 24.9) & - & - & 22 & 36.6 & 0 & 0 & \\
\hline Overweight $(25-29.9)$ & - & - & 37 & 61.7 & 1 & 1.7 & \\
\hline Obese $(30-39.9)$ & - & - & - & - & - & - & \\
\hline \multicolumn{7}{|l|}{ Duration of knee pain } & \multirow{5}{*}{$\begin{array}{l}\chi^{2}=0.678 \\
d . f=2 \\
p=0.712 \\
\text { N.S }\end{array}$} \\
\hline Less than 3 years & - & - & - & - & - & - & \\
\hline $3-6$ years & - & - & 4 & 6.7 & 0 & 0 & \\
\hline $7-10$ years & - & - & 20 & 33.3 & 0 & 0 & \\
\hline More than 10 years & - & - & 35 & 58.3 & 1 & 1.7 & \\
\hline \multicolumn{7}{|l|}{ Which knee is affected? } & \multirow{3}{*}{$\begin{array}{l}\chi^{2}=0.370 \\
\text { d.f }=1 \\
p=0.543 \\
\text { N.S }\end{array}$} \\
\hline One knee & - & - & 16 & 26.7 & 0 & 0 & \\
\hline Both knees & - & - & 43 & 71.7 & 1 & 1.7 & \\
\hline $\begin{array}{l}\text { Are you under any medication for knee } \\
\text { pain }\end{array}$ & & & & & & & \multirow{3}{*}{$\begin{array}{l}\chi^{2}=0.951 \\
\text { d.f }=1 \\
p=0.329 \\
\text { N.S }\end{array}$} \\
\hline Yes & - & - & 30 & 50.0 & 1 & 1.7 & \\
\hline No & - & - & 29 & 48.3 & 0 & 0 & \\
\hline \multicolumn{7}{|l|}{ Are you following any exercise } & \multirow{3}{*}{$\begin{array}{l}\chi^{2}=6.610 \\
\text { d.f=1 } \\
p=0.010 \\
S^{*}\end{array}$} \\
\hline Yes & - & - & 7 & 11.7 & 1 & 1.7 & \\
\hline No & - & - & 52 & 86.7 & 0 & 0 & \\
\hline \multicolumn{7}{|l|}{ If yes, } & \multirow{5}{*}{-} \\
\hline Walking & - & - & 7 & 87.5 & 1 & 12.5 & \\
\hline Cycling & - & - & - & - & - & - & \\
\hline Jogging & - & - & - & - & - & - & \\
\hline Others & - & - & - & - & - & - & \\
\hline
\end{tabular}

${ }^{*} p<0.05, \mathrm{~S}-$ Significant, N.S - Not Significant

Table no 4 and 5 reveals that the association between balance control and duration of knee pain. The finding shows that there was a significant association between balance control and age and history of doing exercise.

DISCUSSION:

The present study result indicated that 31 (51.7\%) of the elderly between the age group of 71 to 75 years, $66.7 \%$ of the elderly were male, $48(80 \%)$ were completed primary education, $48.3 \%$ of the elderly were heavy workers, $63.3 \%$ of the elderly were overweight $36(60 \%)$ of the elderly had knee pain 7 to 10 years.44 (73.3\%) of the elderly had knee OA affected in both knees, 31 (51.7\%) of the elderly taking medication for pain, only 8 $(13.3 \%)$ of the elderly are doing walking exercise and 52 (86.7\%) of the elderly not doing any exercise. Berg Balance Scale was used to assess the balance control of elderly. The finding showed that majority of the elderly 98.33\% had moderate level of balance control. It is affecting their activity of daily living. This was also supported by a study conducted by RS Hinman et, al., on balance impairment in individual with symptomatic knee OA. 33 people above 50 years with OA and 33 controls were participated. WOMAC OA index was used to evaluate knee pain and disability in the OA group. The result of the study demonstrated that individual with knee OA display some impairment in postural control.

\section{CONCLUTION:}

Knee OA is a most common disease which causes a major burden of physical disability. It is incurable which currently available therapeutic measures. The only way for reduction of burden of the disorder is prevention. There is need to take necessary step to increase awareness about the prevention of risk factors. Proper position of knee joint, importance of daily exercise. Regular treatment and exercise could make patients to manage the pain, maintain mobility and maintain physical function. 


\section{REFERENCES:}

1. Van Saase, J. L., Van Romunde, L. K., Cats, A. R. N. O. L. D., Vandenbroucke, J. P., \& Valkenburg, H. A. (1989). Epidemiology of osteoarthritis: Zoetermeer survey. Comparison of radiological osteoarthritis in a Dutch population with that in 10 other populations. Annals of the rheumatic diseases, 48(4), 271280.

2. Liu, C., Wan, Q., Zhou, W., Feng, X., \& Shang, S. (2017). Factors associated with balance function in patients with knee osteoarthritis: An integrative review. International journal of nursing sciences, 4(4), 402-409.

3. Guccione, A. A., Felson, D. T., Anderson, J. J., Anthony, J. M., Zhang, Y., Wilson, P. W., \& Kannel, W. B. (1994). The effects of specific medical conditions on the functional limitations of elders in the Framingham Study. American journal of public health, 84(3), 351-358.

4. Moutzouri, M., Gleeson, N., Billis, E., Tsepis, E., Panoutsopoulou, I., \& Gliatis, J. (2017). The effect of total knee arthroplasty on patients' balance and incidence of falls: a systematic review. Knee Surgery, Sports Traumatology, Arthroscopy, 25(11), 3439-3451.

5. Sibley, K. M., Beauchamp, M. K., Van Ooteghem, K., Straus, S. E., \& Jaglal, S. B. (2015). Using the systems framework for postural control to analyze the components of balance evaluated in standardized balance measures: a scoping review. Archives of physical medicine and rehabilitation, 96(1), 122-132.

6. Levinger, P., Menz, H. B., Wee, E., Feller, J. A., Bartlett, J. R., \& Bergman, N. R. (2011). Physiological risk factors for falls in people with knee osteoarthritis before and early after knee replacement surgery. Knee surgery, sports traumatology, arthroscopy, 19(7), 1082-1089.

7. Xing, D., Xu, Y., Liu, Q., Ke, Y., Wang, B., Li, Z., \& Lin, J. (2016). Osteoarthritis and all-cause mortality in worldwide populations: grading the evidence from a meta-analysis. Scientific reports, 6(1), 1-7.

8. Fitzgerald, G. K., Piva, S. R., \& Irrgang, J. J. (2004). Reports of joint instability in knee osteoarthritis: its prevalence and relationship to physical function. Arthritis care \& research, 51(6), 941-946.

9. Kim, I., Kim, H. A., Seo, Y. I., Song, Y. W., Hunter, D. J., Jeong, J. Y., \& Kim, D. H. (2010). Tibiofemoral osteoarthritis affects quality of life and function in elderly Koreans, with women more adversely affected than men. BMC musculoskeletal disorders, 11(1), 129.

10. Sturnieks, D. L., St George, R., \& Lord, S. R. (2008). Balance disorders in the elderly. Neurophysiologie Clinique/Clinical Neurophysiology, 38(6), 467-478.

11. Sibley, K. M., Straus, S. E., Inness, E. L., Salbach, N. M., \& Jaglal, S. B. (2013). Clinical balance assessment: perceptions of commonly-used standardized measures and current practices among physiotherapists in Ontario, Canada. Implementation Science, 8(1), 33.

12. Hsieh, R. L., Lee, W. C., Lo, M. T., \& Liao, W. C. (2013). Postural stability in patients with knee osteoarthritis: comparison with controls and evaluation of relationships between postural stability scores and international classification of functioning, disability and health components. Archives of physical medicine and rehabilitation, 94(2), 340-346.

13. Pandya, N. K., Piotrowski, G. A., Pottenger, L., \& Draganich, L. F. (2007). Pain relief in knee osteoarthritis reduces the propensity to trip on an obstacle. Gait \& posture, 25(1), 106-111.

14. Hunt, M. A., McManus, F. J., Hinman, R. S., \& Bennell, K. L. (2010). Predictors of single-leg standing balance in individuals with medial knee osteoarthritis. Arthritis care \& research, 62(4), 496-500.

15. Slemenda, C., Brandt, K. D., Heilman, D. K., Mazzuca, S., Braunstein, E. M., Katz, B. P., \& Wolinsky, F. D. (1997). Quadriceps weakness and osteoarthritis of the knee. Annals of internal medicine, 127(2), 97104.

16. Koralewicz, L. M., \& Engh, G. A. (2000). Comparison of proprioception in arthritic and age-matched normal knees.JBJS, 82(11), 1582.

17. Brooks, P. M. (2006). The burden of musculoskeletal disease-a global perspective. Clinical rheumatology, 25(6), 778-781.

18. Williams, S. B., Brand, C. A., Hill, K. D., Hunt, S. B., \& Moran, H. (2010). Feasibility and outcomes of a home-based exercise program on improving balance and gait stability in women with lower-limb osteoarthritis or rheumatoid arthritis: a pilot study. Archives of physical medicine and rehabilitation, 91(1), 106-114. 